\title{
Dietary soya intake alters plasma antioxidant status and lipid peroxidation in postmenopausal women with the metabolic syndrome
}

\author{
Leila Azadbakht ${ }^{1,2 *}$, Masoud Kimiagar ${ }^{3}$, Yadollah Mehrabi ${ }^{4}$, Ahmad Esmaillzadeh ${ }^{1,2}$, Frank B. Hu ${ }^{5,6}$ \\ and Walter C. Willett ${ }^{5,6}$ \\ ${ }^{1}$ Department of Nutrition, School of Health, Isfahan University of Medical Sciences, Isfahan, PO Box 81745, Iran \\ ${ }^{2}$ Nutrition Research Center, Isfahan University of Medical Sciences, Isfahan, Iran \\ ${ }^{3}$ Department of Human Nutrition, School of Nutrition and Food Science, Shaheed Beheshti University of Medical Sciences, \\ Tehran, Iran \\ ${ }^{4}$ School of Public Health, Shaheed Beheshti University of Medical Sciences, Tehran, Iran \\ ${ }^{5}$ Department of Nutrition, Harvard School of Public Health, Boston, MA, USA \\ ${ }^{6}$ Department of Epidemiology, Harvard School of Public Health, Boston, MA, USA
}

(Received 3 January 2007 - Revised 7 March 2007 - Accepted 30 March 2007)

\begin{abstract}
Postmenopausal women with the metabolic syndrome are at high risk of oxidative stress. Several studies have suggested possible antioxidant properties of soya, but little evidence is available regarding the effect of soya on oxidative stress in postmenopausal women with the metabolic syndrome. The objective of the present study was to determine the effects of soya consumption on plasma total antioxidant capacity (TAC) and malondialdehyde (MDA) level in postmenopausal women with the metabolic syndrome. A randomised cross-over trial was undertaken on forty-two postmenopausal women with the metabolic syndrome. Participants were randomly assigned to consume a control (Dietary Approaches to Stop Hypertension; DASH) diet, a soya protein diet, or a soya nut diet, each for 8 weeks. Red meat in the DASH diet (one serving per d) was replaced by soya protein in the soya protein period and by soya nuts in the soya nut period. Significant differences between the end values of the control diet, soya protein diet and soya nut diet were seen for MDA $(0.70,0.64$ and $0.63 \mu \mathrm{mol} / 1$; global $P<0.01)$. The results also showed a significant difference between the end values for TAC (1950, 2030 and $2110 \mu \mathrm{mol} / \mathrm{l}$, respectively; $P<0 \cdot 01)$. The difference from control for TAC was $+4.5 \%(P<0.01)$ in the soya nut period and $+5.8 \%(P<0.01)$ in the soya protein regimen. Both soya nuts and soya protein decreased MDA significantly compared with the control diet (difference from control was $-7.9 \%(P<0.01)$ in the soya nut period and $-9.4 \%(P<0.01)$ in the soya protein diet). We conclude that soya consumption reduces plasma MDA and increases plasma TAC levels in postmenopausal women with the metabolic syndrome.
\end{abstract}

Soya: Oxidative stress: Metabolic syndrome: Postmenopausal women: Antioxidant capacity

The metabolic syndrome is characterised by a constellation of cardiovascular risk factors, including atherogenic dyslipidaemia, abnormal glucose tolerance, hypertension and visceral obesity $^{1}$. Fat accumulation, a serious problem in the metabolic syndrome, is correlated with systemic oxidative stress in man. Oxidative stress may play critical roles in the pathogenesis of various features of the metabolic syndrome ${ }^{2}$, via impairment of glucose uptake in muscle and $\mathrm{fat}^{3}$ and reduction in insulin secretion from pancreatic $\beta$ cells ${ }^{4}$. Increased oxidative stress may also underlie the pathophysiology of hypertension ${ }^{5}$ and atherosclerosis ${ }^{6}$ by directly affecting vascular wall cells. The antioxidant activity of HDL is impaired in the metabolic syndrome $^{7}$, and increased oxidative stress in accumulated fat may contribute to this syndrome. Therefore, the reduction of oxidative stress may be a useful target for new therapies for patients with the metabolic syndrome ${ }^{8}$. Oxidative defence decreases with age because the defence systems may be compromised after the menopause ${ }^{9}$. A reduced antioxidant defence is also seen specifically in postmenopausal women due to the lack of oestrogen ${ }^{10}$. Therefore, postmenopausal women with the metabolic syndrome are at high risk of oxidative stress.

Diet plays an important role in the metabolic syndrome ${ }^{11-13}$. Although many studies have been conducted in patients with the metabolic syndrome ${ }^{14-16}$, only one study addressed the issue of oxidative stress in these patients ${ }^{17}$. Several studies have focused on the effect of diet on oxidative stress, especially the effect of soya consumption ${ }^{18-22}$. The antioxidant properties of soya isoflavones may protect against lipid oxidation ${ }^{18}$ and improve plasma antioxidant status ${ }^{19}$. Some studies have suggested an antioxidant action of soya isoflavones $^{20,21}$ but others demonstrated little or no effect of soya-derived isoflavones on the biomarkers of oxidative 
stress $^{19,22}$. However, most of these studies have focused on healthy subjects and there has been little emphasis regarding the effect of soya consumption on the markers of oxidative stress specifically among postmenopausal women with the metabolic syndrome.

We hypothesised that soya consumption might be beneficial for reducing oxidative stress in the metabolic syndrome. We therefore evaluated the effects of soya consumption, in the form of isolated soya protein and roasted soya nuts with naturally occurring isoflavones, on plasma total antioxidant capacity (TAC) and malondialdehyde (MDA) in postmenopausal women with the metabolic syndrome.

\section{Research design and methods}

\section{Participants}

A total of 120 Tehranian postmenopausal women with the metabolic syndrome were screened for inclusion in the study. The present study was conducted in Tehran, Iran. The women were living in the same district of Tehran, so they were approximately in the same level of socio-cultural characteristics (moderate level). Women were considered postmenopausal if menstrual periods had been absent for more than 1 year and follicle-stimulating hormone, serum luteinising hormone, testosterone and oestradiol levels confirmed their status $^{23}$. The metabolic syndrome was defined according to Adult Treatment Panel III guidelines ${ }^{24}$ : (1) abdominal adiposity (waist circumference $>88 \mathrm{~cm}$ ); (2) low levels of serum HDL-cholesterol $(<500 \mathrm{mg} / \mathrm{l})$; (3) hypertriacylglycerolaemia $(\geq 1500 \mathrm{mg} / \mathrm{l})$; (4) elevated blood pressure $(\geq 130 /$ $85 \mathrm{mmHg}$ ); (5) impaired glucose homeostasis $(\geq 1100 \mathrm{mg} / \mathrm{l})$. To be enrolled in the study, patients had to have three or more of the above-mentioned criteria to be classified as having the metabolic syndrome. Exclusion criteria were any secondary cause of hyperglycaemia, current or previous (in the preceding 6 months) use of oestrogen therapy, treatment with insulin or oral hypoglycaemic agents, untreated hypothyroidism, smoking, kidney or liver diseases or breast cancer. Finally, forty-two women were included in the present study; all of them had all five components of the metabolic syndrome. All participants provided informed written consent.
The present study was approved by the research council and ethical committee of the National Nutrition and Food Technology Research Institute of Shaheed Beheshti University of Medical Sciences.

\section{Study procedures}

We used a randomised cross-over design. After 3 weeks of run-in on a usual diet (average of $55 \%$ energy from carbohydrate, $15 \%$ energy from protein and $30 \%$ energy from fat), we randomly assigned women to a control diet (diet A, a red meat-Dietary Approaches to Stop Hypertension (DASH) diet), a DASH diet with soya nuts (diet B, soya nut period) or a DASH diet with soya protein (diet C, soya protein period), each one for 8 weeks (The rationale of intervention duration was based on previous interventions and we thought that in longer periods subjects may not follow the study completely.) Each woman received all three diets and had two wash-out periods (each wash-out for 4 weeks; the rationale of wash-out duration was based on previous studies) between the three diets. We set six different sequences of diet intakes (ABC, ACB, BCA, BAC, CBA, CAB) (Fig. 1). The randomisation was conducted at the end of the run-in.

Measurements were obtained before run-in, after run-in (baseline), after each diet and after each wash-out. Baseline measurements were considered after run-in and after each wash-out. Participants were asked not to change their habitual physical activity level for the duration of the study. Patients recorded their physical activities for $3 \mathrm{~d}$ each month.

\section{Diets}

We used three diets:

(1) Control diet: this diet was a DASH diet with $55 \%$ energy from carbohydrates, $17 \%$ energy from protein, and $28 \%$ energy from total fat on average. This diet had one serving of red meat per $d$ (red meat-DASH) and was rich in fruits, vegetables, whole grains, low-fat dairy products, and low in saturated fat, total fat, cholesterol, refined grains and sweets. The amount of $\mathrm{Na}$ intake was $2400 \mathrm{mg} / \mathrm{d}^{25}$.

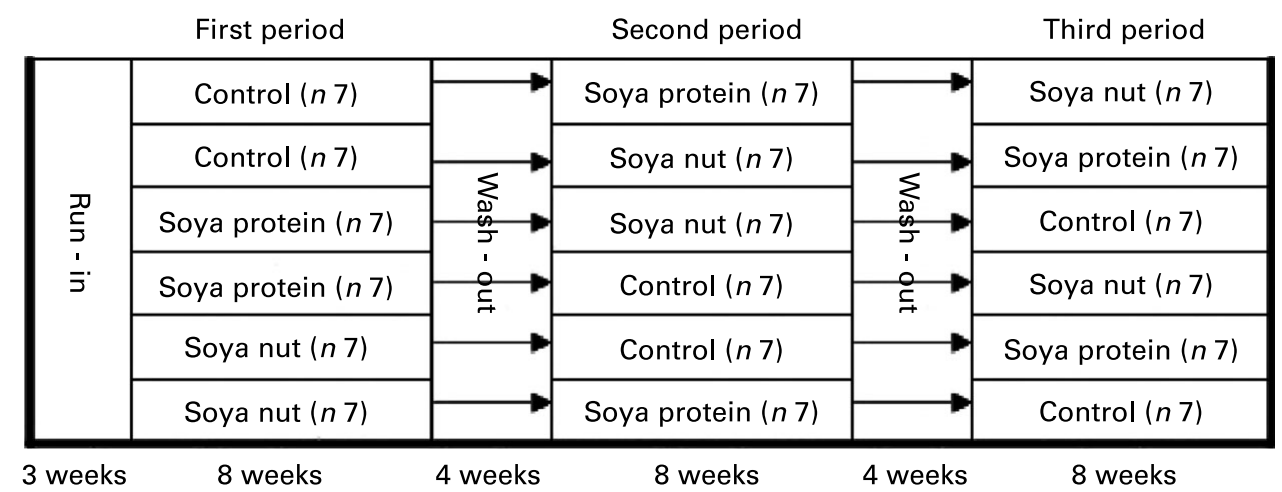

Fig. 1. Design of the study. The control diet was a Dietary Approach to Stop Hypertension diet. This diet was rich in fruits, vegetables, whole grains, low-fat dairy products, and low in red meat, saturated fat, total fat, cholesterol, refined grains and sweets. The amount of Na intake was $2400 \mathrm{mg} / \mathrm{d}$. The diet with soya nuts was the same as the control diet but we replaced red meat with soya nuts. Every $30 \mathrm{~g}$ soya nuts was considered as one serving of moderate-fat meat. The diet with soya protein was the same as the control diet but we replaced red meat with soya protein. Every $30 \mathrm{~g}$ soya protein was considered as one serving of low-fat meat. 
(2) Diet with soya nuts: this diet was the same as the control diet but we replaced red meat by soya nuts; a serving of $30 \mathrm{~g}$ soya nuts was considered as one serving of red meat $^{26}$.

(3) Diet with soya protein: this diet was the same as the control diet but we replaced red meat by soya protein. Every $30 \mathrm{~g}$ soya protein was considered as one serving of red meat $^{26}$.

The nutrient composition of soya nuts and soya protein consumed by the study participants, based on our analysis, is shown in Table 1.

Energy requirements of each participant were calculated individually based on equations suggested by the Institute of Medicine, Food and Nutrition Board ${ }^{27}$. The participants were visited every 2 weeks, for $45-60 \mathrm{~min} /$ patient. They were in touch with the study nutritionist daily by phone. For measuring food intake, $3 \mathrm{~d}$ diet records were used at baseline and during intervention for each month. Every participant had to bring in her $3 \mathrm{~d}$ diet record and physical activity records every month, where they were reviewed by the study staff and used for checking diet compliance.

The study nutritionist explained the benefits of each diet for participants. They also received education in using an exchange list of foods, and in writing food diaries. The diets were individually prescribed using a 'calorie count' system and an exchange list was given to each patient for exchanging the food items and calculating calories. A $7 \mathrm{~d}$ menu cycle at six energy levels (7530, 7950, 8370, 8790, 9200 and $9620 \mathrm{~kJ} ; 1800,1900,2000,2100,2200$ and $2300 \mathrm{kcal})$ was developed for each diet.

To maximise treatment fidelity, group discussions were performed monthly, in which the food items that should be eaten were emphasised. Women also received education on the methods of preparing soya protein according to their menu and were encouraged to follow their diets. The investigators randomly took part in the counselling sessions and monitored the messages that the nutritionist was giving to each group. Patient compliance was assessed by analysing the $3 \mathrm{~d}$ food record diaries monthly and by the attendance at the meetings and monthly visits.

\section{Measurements}

Body weight was measured while the subjects were minimally clothed, without shoes, using digital scales and recorded to the nearest $0 \cdot 1 \mathrm{~kg}$. Height was measured in a standing position, without shoes, using a tape meter while the shoulders were

Table 1. Nutrient composition of soya protein and soya nuts used in the intervention

\begin{tabular}{lcc}
\hline Nutrients/30g & Soya protein & Soya nuts \\
\hline Protein $(\mathrm{g})$ & $15 \cdot 0$ & $11 \cdot 3$ \\
Fat $(\mathrm{g})$ & $0 \cdot 3$ & 7 \\
Fibre $(\mathrm{g})$ & 10 & 9 \\
Na $(\mathrm{mg})$ & 9 & 10 \\
Total phyto-oestrogens $(\mathrm{mg})$ & 84 & 102 \\
Glycitein $(\mathrm{mg})$ & 8 & 9 \\
Genistein $(\mathrm{mg})$ & 43 & 53 \\
Daidzein $(\mathrm{mg})$ & 33 & 40 \\
\hline
\end{tabular}

in a normal state. Waist circumference was measured to the nearest $0.1 \mathrm{~cm}$ at the narrowest level over light clothing, using an unstretched tape meter, without any pressure to the body surface. The ferric-reducing ability of plasma method according to Benzie \& Strain was used for plasma TAC measurement ${ }^{28}$. The EDTA plasma samples were stored at $-70^{\circ} \mathrm{C}$ until MDA measurements were determined by HPLC according to the method of Wong et al. ${ }^{29}$. Plasma phyto-oestrogen levels were measured by HPLC according to Franke et al. ${ }^{30,31}$ to check the soya trial compliance.

\section{Statistical analysis}

We used general linear models (repeated-measures ANOVA) to compare means of the markers of oxidative stress at the end of the soya nut, soya protein and control diets. Then, we used paired $t$ tests to compare the end-of-treatment values of each group with each other group. The percentage change for each variable was also calculated by the formula $(\mathrm{E}-\mathrm{B}) / \mathrm{B} \times 100$, where $\mathrm{E}$ is the end-of-treatment values and $\mathrm{B}$ is the baseline values. We compared groups using the percentage change in both repeated-measures ANOVA and using paired $t$ tests. We also determined the mean percentage change differences, which were derived by calculating the differences in percentage change for each variable in pairwise group comparisons. This parameter gives the most direct estimate of the difference in response in comparing groups. We also calculated the percentage difference compared with control for each group (both soya protein and soya nut). The percentage difference compared with control for each variable was also calculated by the formula $(\mathrm{X}-\mathrm{C})$ / $\mathrm{C} \times 100$, where $\mathrm{X}$ is the end values of the soya protein or soya nut group and $C$ is the end values of the control group. Interactions between soya intake and weight were not significant for any of the markers. Period effect and carryover effects were tested using the appropriate general linear models.

Pearson correlation coefficients were used to evaluate the relationship between soya-derived phyto-oestrogen intake (calculated from self-reported soya intake in $3 \mathrm{~d}$ diet records) and plasma phyto-oestrogen levels. All results were considered significant if the two-tailed $P$ value was $<0 \cdot 05$. Statistical analysis was performed using SPSS for Windows version 13.0 (SPSS Inc., Chicago, IL, USA) and SAS version 8.2 (1999; SAS Institute Inc., Cary, NC, USA).

\section{Results}

All participants (forty-two postmenopausal women with the metabolic syndrome) completed the entire cross-over study. Characteristics of the women at baseline are presented in Table 2. Calculated nutrient content and food-group servings of the $3 \mathrm{~d}$ diet records according to the patients' reports are shown in Table 3 . Both the soya nut and soya protein diets were well tolerated. Only one individual complained of feeling bloated during the soya protein period.

Participants' weights in the control, soya protein and soya nut periods were 71.6 (SE 1.5), 71.5 (SE 1.5) and 71.3 (SE 1.5) $\mathrm{kg}$ at baseline and 70.1 (SE 0.9), 70.7 (SE 0.9) and 70.4 (SE 0.8) $\mathrm{kg}$ at the end of the trials, which shows no significant changes during the trials. 
Table 2. Baseline characteristics of participants

(Mean values with their standard errors)

\begin{tabular}{lccc}
\hline Characteristic & Mean & SE & Range \\
\hline Age (years) & 57 & $0 \cdot 3$ & $51-60$ \\
Weight $(\mathrm{kg})$ & 71 & 1.5 & $62-78$ \\
BMI (kg $\left./ \mathrm{m}^{2}\right)$ & 28 & 0.2 & $26 \cdot 8-29.5$ \\
Follicle-stimulating hormone (IU/l) & 72 & $4 \cdot 8$ & $66-83$ \\
\hline
\end{tabular}

Fig. 2 represents the baseline and end-of-trial values of MDA in the three different periods. There were no significant differences in the baseline values of MDA $(0.76,0.73$ and $0.75 \mu \mathrm{mol} / \mathrm{l}$; global $P=0 \cdot 16$ ). Significant differences between the end values of the control diet, soya protein regimen and soya nut consumption were seen $(0.70,0.64$ and $0.63 \mu \mathrm{mol} / \mathrm{l}$; global $P<0 \cdot 01)$. Paired comparisons of the diets showed a significant difference between the end values of the control and soya protein diets $(P<0 \cdot 01)$, and control and soya nut diets $(P<0 \cdot 01)$. No significant differences were seen between the soya protein and soya nut diets $(P=0.44)$ with regard to the end values.

Fig. 3 shows the baseline and end-of-diet values of TAC in the three different periods. The results showed a significant difference between the baseline values (1890, 1900 and $1950 \mu \mathrm{mol} / \mathrm{l}$, respectively; global $P<0 \cdot 01)$ and also end-ofdiet values (1950, 2030 and $2110 \mu \mathrm{mol} / \mathrm{l}$, respectively; global $P<0 \cdot 01)$. Paired comparison of the diets showed a significant difference with regard to the end values between the control and soya protein diets $(P<0.01)$, control and soya nut diets $(P<0.01)$, and soya protein and soya nut diets $(P<0 \cdot 01)$.
Fig. 4 shows the percentage change of MDA and TAC in the three diets. Percentage changes in the control, soya protein and soya nut diets were significantly different for TAC $(+3 \cdot 2$, +7.3 and $+8.5 \%$; global $P<0.01)$ and MDA $(-7 \cdot 0,-12 \cdot 0$ and $-14.0 \%$; global $P<0.01)$. The difference from control for TAC was $+4.5 \%(P<0.01)$ in the soya nut period and $5.8 \%(P<0.01)$ on the soya protein regimen. Both soya nuts and soya protein reduced MDA significantly compared with the control diet (difference from control was $-7.9 \%$ $(P<0.01)$ in the soya nut period and $-9.4 \%(P<0.01)$ on the soya protein diet). The results were not changed when we adjusted the means for the dietary $\mathrm{Zn}$ intake in further models (data not shown).

Compared with the control diet, plasma phyto-oestrogen increased significantly after the soya nut regimen (percentage change $+64 \% ; P<0.01)$ and the soya protein diet (percentage change $+48 \% ; P<0 \cdot 01$ ) (data not shown).

\section{Discussion}

The present study assessed the effects of soya protein and soya nut consumption on plasma TAC and MDA as a biomarker of oxidative stress in postmenopausal women with the metabolic syndrome. The present data suggested that both soya protein and soya nut intake raised the TAC and decreased MDA. This result is in line with a recent paper, which showed that plasma TAC was modestly higher $(10 \%)$ at the end of the soya protein phases than during the animal protein phases, regardless of the isoflavone content of the diet ${ }^{19}$. An earlier multiple regression analysis also showed that after 12 weeks of soya protein consumption TAC was increased ${ }^{32}$. A report on patients with hypercholesterolaemia ${ }^{33}$ suggested a reduction in lipid peroxidation as estimated by thiobarbituric

Table 3. Dietary intake of participants separately by intervention period

\begin{tabular}{|c|c|c|c|c|c|}
\hline Dietary intakes (per d) & Control $(n 42)^{\star}$ & Soya protein $(n 42) \dagger$ & Soya nut ( $n$ 42) $\ddagger$ & $P \S$ & Wash-out (n 42)\| \\
\hline Soya protein $(g / d)$ & 0 & 30 & 0 & - & 0 \\
\hline Soya nuts $(g / d)$ & 0 & 0 & 30 & - & 0 \\
\hline \multicolumn{6}{|l|}{ Nutrients } \\
\hline Energy (kJ) & 8598 & 8531 & 8573 & 0.62 & 8694 \\
\hline Energy (kcal) & 2055 & 2039 & 2049 & 0.62 & 2078 \\
\hline Protein (\% energy) & 17 & 17 & 17 & 0.71 & 15 \\
\hline Total fat ( $\%$ energy) & 28 & 25 & 29 & 0.73 & 31 \\
\hline Saturated fat (\% energy) & 7 & 5 & 5 & 0.61 & 14 \\
\hline Polyunsaturated fat (\% energy) & 8 & 8 & 11 & 0.78 & 7 \\
\hline Monounsaturated fat (\% energy) & 10 & 10 & 10 & 0.73 & 9 \\
\hline Cholesterol (mg) & 189 & 173 & 175 & 0.51 & 300 \\
\hline Carbohydrate (\% energy) & 55 & 58 & 57 & 0.79 & 54 \\
\hline Fibre (g) & 25 & 32 & 33 & $<0.05$ & 11 \\
\hline $\mathrm{K}(\mathrm{mg})$ & 4395 & 4416 & 4426 & 0.31 & 1546 \\
\hline $\mathrm{Ca}(\mathrm{mg})$ & 1209 & 1219 & 1227 & 0.49 & 750 \\
\hline $\mathrm{Fe}(\mathrm{mg})$ & 25 & 23 & 21 & 0.16 & 24 \\
\hline $\mathrm{Mg}(\mathrm{mg})$ & 341 & 325 & 351 & 0.22 & 162 \\
\hline $\mathrm{Zn}(\mathrm{mg})$ & 8.9 & 8.8 & 8.7 & 0.31 & 8.6 \\
\hline Vitamin A (mg retinol) & 3.06 & 3.09 & 3.08 & 0.12 & 1.36 \\
\hline Vitamin C (mg) & 123 & 125 & 119 & 0.32 & 79 \\
\hline Vitamin E (mg) & 8.7 & 8.5 & 8.6 & 0.22 & $7 \cdot 8$ \\
\hline
\end{tabular}




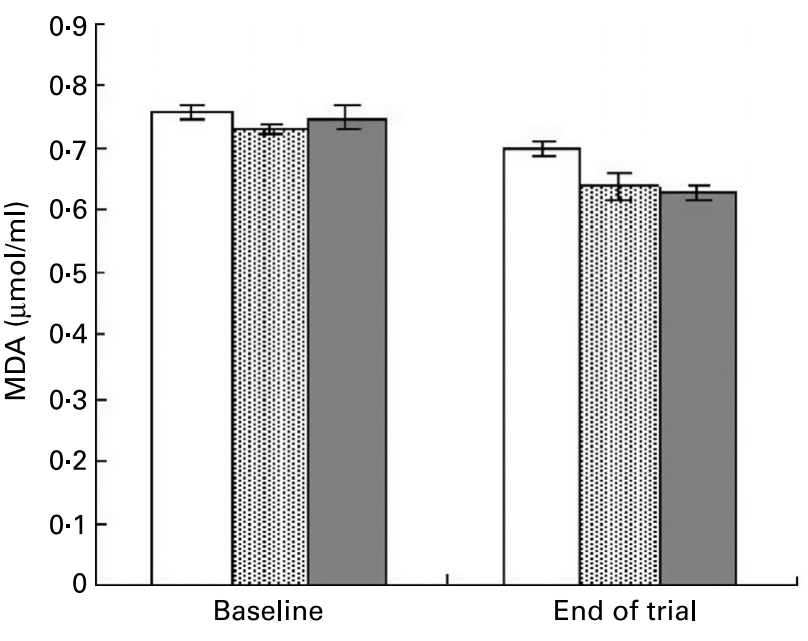

Fig. 2. Baseline and end-of-trial values of malondialdehyde (MDA) in three different periods. The control diet $(\square)$ was a Dietary Approach to Stop Hypertension diet. This diet was rich in fruits, vegetables, whole grains, low-fat dairy products, and low in red meat, saturated fat, total fat, cholesterol, refined grains and sweets. The diet with soya nuts $(\square)$ was the same as the control diet but we replaced red meat with soya nuts. The diet with soya protein (國) was the same as the control diet but we replaced red meat with soya protein. Values are means, with their standard errors represented by vertical bars. $P$ values resulted from paired $t$ tests. The global $P$ value for the baseline values of MDA was 0.16 and the global $P$ value for the end values of MDA was $<0.05$. There were no significant differences in baseline values among the three groups. There was a significant difference between the soya protein and control diets $(P<0.01)$ as well as between the soya nut and control diets $(P<0.05)$, but there was no difference between the soya protein and soya nut diets $(P=0.44)$.

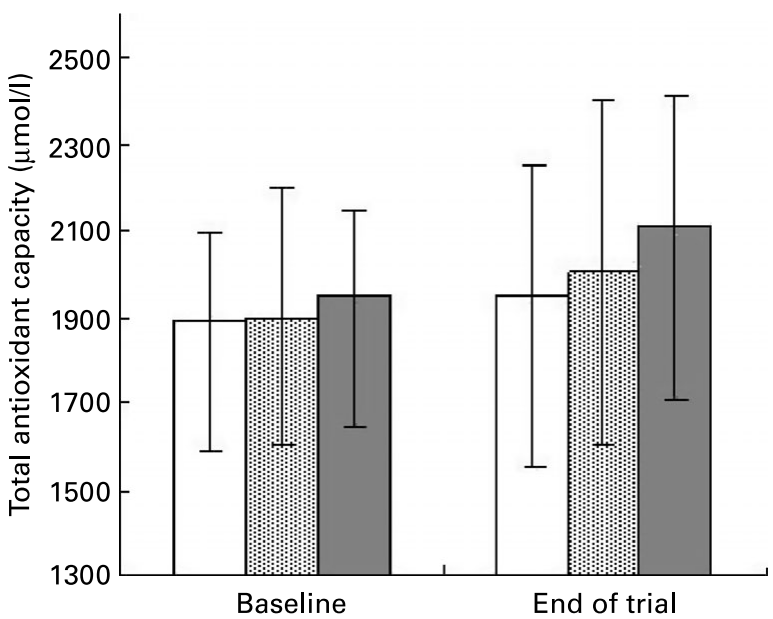

Fig. 3. Baseline and end-of-trial values of the plasma total antioxidant capacity (TAC) in three different periods. The control diet $(\square)$ was a Dietary Approach to Stop Hypertension diet. This diet was rich in fruits, vegetables, whole grains, low-fat dairy products, and low in red meat, saturated fat, total fat, cholesterol, refined grains and sweets. The diet with soya nuts $(\square)$ was the same as the control diet but we replaced red meat with soya nuts. The diet with soya protein (圈) was the same as the control diet but we replaced red meat with soya protein. Values are means, with their standard errors represented by vertical bars. $P$ values resulted from paired $t$ tests. The general $P$ value for the baseline values of TAC was $<0.05$ and the general $P$ value for the end values of TAC was $<0.05$. There was no significant difference between the baseline values of the control and soya protein periods $(P=0.54)$ but there was a significant difference between the control and soya nut diets as well as between the soya protein and soya nut diets (both $P<0.01$ ). The end values of TAC were significantly different between the control and soya nut, between the control and soya protein, and between the soya protein and soya nut diets (all $P<0.01$ ).

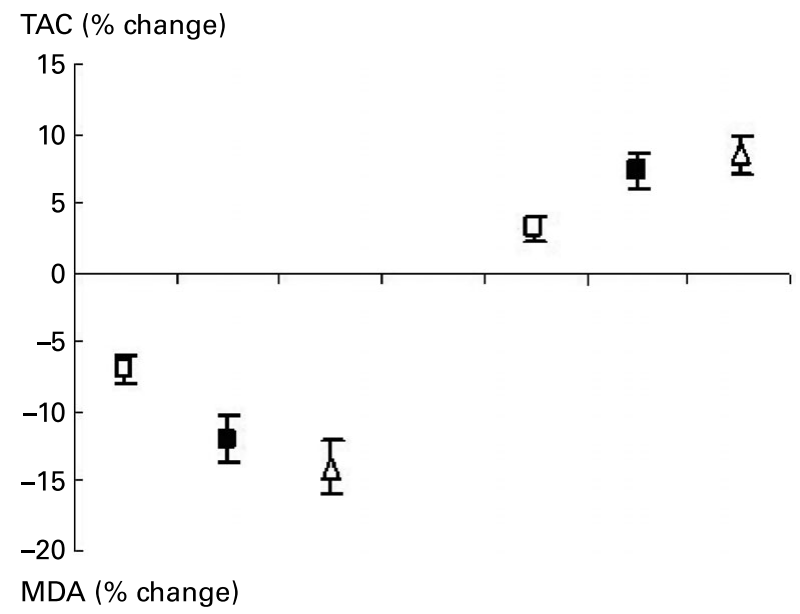

Fig. 4. Percentage change in malondialdehyde (MDA) and plasma total antioxidant capacity (TAC) in three diets: control $(\square)$, soya protein $(\square)$ and soya nut $(\Delta)$. The control diet was a Dietary Approach to Stop Hypertension diet. This diet was rich in fruits, vegetables, whole grains, low-fat dairy products, and low in red meat, saturated fat, total fat, cholesterol, refined grains and sweets. The diet with soya nuts was the same as the control diet but we replaced red meat with soya nuts. The diet with soya protein was the same as the control diet but we replaced red meat with soya protein. Values are means, with their standard errors represented by vertical bars. There was a significant effect of diet on TAC $(P<0.01)$ and MDA $(P<0.01)$ (repeatedmeasures ANOVA).

acid-reactive substances, after 6 weeks of soya milk consumption. Investigators mentioned that the antioxidant activity of soya might be related to its phyto-oestrogens or phytic acid content $^{34,35}$. The antioxidant effect of soya phyto-oestrogens may be due to donating hydrogen atoms to free radicals, so making them less reactive ${ }^{36}$. Another possible mechanism, shown in a mouse model $^{37}$, may be to increase antioxidant enzyme concentrations. In another way, the phytate in soya may quench free radicals because of its metal-chelating ability $^{34}$. Nevertheless, Engelman et al. ${ }^{22}$ showed that neither phytate nor isoflavones in soya protein isolate had a significant effect in reducing oxidative damage. It seems that the absorption of phytate in human is very low ${ }^{22}$.

The soya products used in the present study contained both protein and isoflavones. According to previous reports, full-fat flaxseed, despite high concentrations of antioxidants, had no significant effect on thiobarbituric acid-reactive substances $^{38,39}$, which might be related to the high content of $\alpha$-linolenic acid in the full-fat flaxseed. In the present study, the effects of both soya protein and soya nuts on the markers of oxidative stress and TAC were similar, despite slightly higher amounts of phyto-oestrogens in soya nuts. Similarly, this may be due to the higher fat content of soya nuts.

In contrast to the present findings, Vega-Lopez et al. ${ }^{19}$ reported higher amounts of MDA after isoflavone-supplemented dietary periods and Wiseman et al. ${ }^{21}$ reported no significant change in plasma MDA after soya consumption regardless of dietary isoflavones. In the present study, participants had the metabolic syndrome, which is associated with higher level of MDA. However, healthy subjects participated in the Wiseman et al. study ${ }^{21}$. Conflicting results in different studies may be due to subject selection, doses of isoflavones and even interindividual variation in the ability to metabolise 
daidzein to equol ${ }^{21,22}$. Equol has antioxidant characteristics. So, higher amounts of equol production may increase the plasma $\mathrm{TAC}^{21,22}$.

Moreover, some human subjects have higher rates of lipid peroxidation than others, even when consuming similar diets ${ }^{40}$. Kris-Etherton \& West ${ }^{41}$ mentioned that antioxidants may have beneficial effects on other pathways; for example, soya antioxidants may increase endothelial NO synthase activity which is associated with enhanced endothelial function.

There are multiple biomarkers of oxidative stress, which have strengths and limitations ${ }^{42}$. There appears to be agreement that plasma concentrations of $\mathrm{F}_{2}$-isoprostanes may be the best biomarker of lipid peroxidation in healthy human subjects ${ }^{43,44}$. Wiseman et $\mathrm{al}^{21}$ in a cross-over trial on healthy subjects concluded that the consumption of soya containing naturally occurring amounts of phyto-oestrogens reduced $\mathrm{F}_{2}$-isoprostane concentrations. Another cross-over study showed that dark soya sauce decreased $\mathrm{F}_{2}$-isoprostane more than placebo in healthy subjects ${ }^{45}$. We used plasma MDA concentration as a lipid peroxidation marker, because previous investigators suggested that this marker is probably best suited for use in clinical conditions such as the metabolic syndrome, where there is increased lipid peroxidation and thus elevated MDA production $^{46}$. However, plasma MDA reduction is an indirect marker of lipid peroxidation, and this result should be confirmed by direct assessment of lipid peroxidation in future studies.

Presently, no marker of oxidative stress can indicate both antioxidant status and oxidative stress ${ }^{47}$; therefore, we evaluated TAC for assessing antioxidant status and MDA for measuring oxidative stress.

In the present study in all three diet periods, participants consumed the DASH diet, which includes many different antioxidants. Therefore, the possible interaction between different antioxidants in the body, which may increase the overall antioxidant status and obscure the effect of soya, is one of the limitations of the present study.

Soya products have gained considerable attention for their phyto-oestrogen contents and their possible role in reducing CVD risks ${ }^{48,49}$. Reduction of oxidative stress status may be one of the possible mechanism which needs further investigation. One of the major advantages of the present study and the consistent response of plasma TAC and MDA is that the subjects selected had increased oxidative stress resulting from the metabolic syndrome.

The acute effects on plasma TAC of the consumption of flavonoid-rich foods may be explained by changes in the concentration of the metabolic antioxidant uric acid. On the other hand, fructose has been known for more than 30 years to increase plasma urate levels consequent to its rapid metabolism by fructokinase. Fructose metabolism in this manner leads to a transient decrease in hepatic ATP and inorganic phosphate, which are important inhibitors of $5^{\prime}$-nucleotidase and AMP deaminase, respectively, and thus increased degradation of AMP to uric acid. High levels of methylxanthines in flavonoid-rich foods and their rapid absorption and metabolism to methyl uric acid derivatives could significantly increase plasma TAC $^{50}$. However, we did not measure uric acid levels in the present study.

In conclusion, the present findings suggest that substituting soya products instead of red meat in the DASH eating pattern may reduce MDA and increase the TAC in postmenopausal women with the metabolic syndrome.

\section{Acknowledgements}

The authors express appreciation to the participants of the present study for their enthusiastic support. None of the authors have any personal or financial conflicts of interest. The study was supported by a grant from the National Nutrition and Food Technology Research Institute, Shaheed Beheshti University of Medical Sciences.

\section{References}

1. Ruotolo G \& Howard BV (2002) Dyslipidemia of the metabolic syndrome. Curr Cardiol Rep 4, 494-500.

2. Brownlee M (2001) Biochemistry and molecular cell biology of diabetic complications. Nature 414, 813-820.

3. Maddux BA, See W, Lawrence JC Jr, Goldfine AL, Godlfine ID \& Evans JL (2001) Protection against oxidative stress-induced insulin resistance in rat L6 muscle cells by micromolar concentrations of $\alpha$-lipoic acid. Diabetes 50, 404-410.

4. Matsuoka T, Kajimoto Y, Watada H, Kaneto H, Kishimoto M, Umayahara Y, Fujitani Y, Kamada T, Kawamori R \& Yamasaki Y (1997) Glycation-dependent, reactive oxygen species-mediated suppression of the insulin gene promoter activity in HIT cells. J Clin Invest 99, 144-150.

5. Nakazono K, Watanabe N, Matsuno K, Sasaki J, Sato T \& Inoue M (1991) Does superoxide underlie the pathogenesis of hypertension? Proc Natl Acad Sci USA 88, 10045-10048.

6. Ohara Y, Peterson TE \& Harrison DG (1993) Hypercholesterolemia increases endothelial superoxide anion production. $J$ Clin Invest 91, 2546-2551.

7. Hansel B, Giral P, Nobecourt E, Chantepie S, Bruckert E, Chapman MJ \& Kontush A (2004) Metabolic syndrome is associated with elevated oxidative stress and dysfunctional dense high-density lipoprotein particles displaying impaired antioxidative activity. J Clin Endocrinol Metab 89, 4963-4971.

8. Furukawa S, Fujita T, Shimabukuro M, Iwaki M, Yamada Y, Nakajima $Y$, Nakayama O, Makishima M, Matsuda M \& Shimomura I (2004) Increased oxidative stress in obesity and its impact on metabolic syndrome. $J$ Clin Invest 114, $1752-1761$.

9. Berliner JA \& Heinecke JW (1996) The role of oxidized lipoproteins in atherogenesis. Free Radic Biol Med 20, 707-727.

10. Goudev A, Kyurkchiev S, Gergova V, Karshelova E, Georgiev D, Atar D, Kehayov I \& Nachev C (2000) Reduced concentrations of soluble adhesion molecules after antioxidant supplementation in postmenopausal women with high cardiovascular risk profiles a randomized double-blind study. Cardiology 94, 227-232.

11. Azadbakht L, Mirmiran P, Esmaillzadeh A \& Azizi F (2005) Dairy consumption is favorably associated with metabolic syndrome in Tehranian adults. Am J Clin Nutr 82, 523-530.

12. Esmaillzadeh A, Mirmiran P \& Azizi F (2005) Whole-grain intake and the prevalence of hypertriglyceridemic waist phenotype in Tehranian adults. Am J Clin Nutr 81, 55-63.

13. Riccardi G \& Rivellese AA (2000) Dietary treatment of the metabolic syndrome - the optimal diet. Br J Nutr 83, S143-S148.

14. Esposito K, Marfella R, Citotola M, et al. (2004) Effect of a Mediterranean-style diet on endothelial dysfunction and markers of vascular inflammation in the metabolic syndrome: a randomized trail. JAMA 292, 1440-1446.

15. Azadbakht L, Mirmiran P, Esmaillzadeh A, Azizi T \& Azizi F (2005) Beneficial effects of a Dietary Approach to Stop Hypertension (DASH) eating plan on features of metabolic syndrome. Diabetes Care 28, 2823-2831. 
16. Klimes I \& Sebokova E (1995) The importance of diet therapy in the prevention and treatment of manifestations of metabolic syndrome X. Vnitr Lek 41, 136-140.

17. Roberts CK, Won D, Pruthi S, Kurtovic S, Sindhu RK, Vaziri ND \& Barnard RJ (2006) Effect of a short-term diet and exercise intervention on oxidative stress, inflammation, MMP-9, and monocyte chemotactic activity in men with metabolic syndrome factors. J Appl Physiol 100, 1657-1665.

18. Jenkins DJ, Kendall CW, Garsetti M, et al. (2000) Effect of soy protein foods on low-density lipoprotein oxidation and ex vivo sex hormone receptor activity - a controlled crossover trial. Metabolism 49, 537-543.

19. Vega-Lopez S, Yeum KJ, Lecker JL, Ausman LM, Johnson EJ, Devaraj S, Jialal I \& Lichtenstein AH (2005) Plasma antioxidant capacity in response to diets high in soy or animal protein with or without isoflavones. Am J Clin Nutr 81, 43-49.

20. Mahn K, Borras C, Knock GA, et al. (2005) Dietary soy isoflavone induced increases in antioxidant and eNOS gene expression lead to improved endothelial function and reduced blood pressure in vivo. FASEB $J \mathbf{1 9}, 1755-1757$.

21. Wiseman H, O'Reilly JD, Adlercreutz H, Mallet AI, Bowey EA, Rowland IR \& Sanders TA (2000) Isoflavone phytoestrogens consumed in soy decrease $\mathrm{F}(2)$-isoprostane concentrations and increase resistance of low-density lipoprotein to oxidation in humans. Am J Clin Nutr 72, 395-400.

22. Engelman HM, Alekel DL, Hanson LN, Kanthasamy AG \& Reddy MB (2005) Blood lipid and oxidative stress responses to soy protein with isoflavones and phytic acid in postmenopausal women. Am J Clin Nutr 81, 590-596.

23. Rozenberg S, Bosson D, Peretz A, Caufriez A \& Robyn C (1988) Serum levels of gonadotrophins and steroid hormones in the post-menopause and later life. Maturitas 10, 215-224.

24. Expert Panel on Detection, Evaluation, and Treatment of High Blood Cholesterol in Adults (2001) Executive Summary of The Third Report of The National Cholesterol Education Program (NCEP) Expert Panel on Detection, Evaluation, And Treatment of High Blood Cholesterol In Adults (Adult Treatment Panel III). JAMA 285, 2486-2497.

25. Karanja NM, Obarzanek E, Lin PH, et al. (1999) Descriptive characteristics of the dietary patterns used in the Dietary Approaches to Stop Hypertension trial. J Am Diet Assoc 99, S60-S68.

26. Mahan LK \& Escott-Stump S (2004) Appendix. In Krause's Food Nutrition and Diet Therapy, 11th ed., pp. 1267-1268 [LK Mahan and S Escott-Stump, editors]. Philadelphia, PA: WB Saunders.

27. Institute of Medicine \& Food and Nutrition Board (2002) Dietary Reference Intake for Energy, Carbohydrate, Fiber, Fat, Fatty Acids, Cholesterol, Protein, and Amino Acids. Washington, DC: The National Academies Press.

28. Benzie IF \& Strain JJ (1996) The ferric reducing ability of plasma (FRAP) as a measure of "antioxidant power": the FRAP assay. Anal Biochem 239, 70-76.

29. Wong SHY, Knight JA, Hopfer SM, Zaharia O, Leach CN Jr \& Sunderman FW Jr (1987) Lipoperoxides in plasma as measured by liquid-chromatographic separation of malondialdehyde-thiobarbituric acid adduct. Clin Chem 33, 214-220.

30. Franke AA, Custer LJ \& Tanaka Y (1998) Isoflavones in human breast milk and other biological fluids. Am J Clin Nutr 68, Suppl. 6, 1466S-1473S.

31. Franke AA, Custer LJ, Wang W \& Shi CY (1998) HPLC analysis of isoflavonoids and other phenolic agents from foods and from human fluids. Proc Soc Exp Biol Med 217, 263-273.

32. Swain JH, Alekel DL, Dent SB, Peterson CT \& Reddy MB (2002) Iron indexes and total antioxidant status in response to soy protein intake in perimenopausal women. Am J Clin Nutr 76, $165-171$.
33. Bricarello LP, Kasinski N, Bertolami MC, Faludi A, Pinto LA, Relvas WG, Izar MC, Ihara SS, Tufik S \& Fonseca FA (2004) Comparison between the effects of soy milk and non-fat cow milk on lipid profile and lipid peroxidation in patients with primary hypercholesterolemia. Nutrition 20, 200-204.

34. Rufer CE \& Kulling SE (2006) Antioxidant activity of isoflavones and their major metabolites using different in vitro assays. J Agric Food Chem 54, 2926-2931.

35. Porres JM, Stahl CH, Cheng WH, Fu Y, Roneker KR, Pond WG \& Lei XG (1999) Dietary intrinsic phytate protects colon from lipid peroxidation in pigs with a moderately high dietary iron intake. Proc Soc Exp Biol Med 221, 80-86.

36. Mitchell JH, Gardner PT, McPhail DB, Morrice PC, Collins AR \& Duthie GG (1998) Antioxidant efficacy of phytoestrogens in chemical and biological model systems. Arch Biochem Biophys 360, $142-148$.

37. Cai Q \& Wei H (1996) Effect of dietary genistein on antioxidant enzyme activities in SENCAR mice. Nutr Cancer 25, 1-7.

38. Cunnane SC, Hamadeh MJ, Liede AC, Thompson LU, Wolever TM \& Jenkins DJ (1995) Nutritional attributes of traditional flaxseed in healthy young adults. Am J Clin Nutr 61, 62-68.

39. Cunnane SC, Ganguli S, Menard C, Liede AC, Hamadeh MJ, Chen ZY, Wolever TM \& Jenkins DJ (1993) High $\alpha$-linolenic acid flaxseed (Linum usitatissimum): some nutritional properties in humans. Br J Nutr 69, 443-453.

40. Roberts LJ II \& Morrow JD (1997) The generation and actions of isoprostanes. Biochim Biophys Acta 1345, 121-135.

41. Kris-Etherton PM \& West SG (2005) Soy protein with or without isoflavones: in search of a cardioprotective mechanism of action. Am J Clin Nutr 81, 5-6.

42. Therond P, Bonnefont-Rousselot D, Davit-Spraul A, Conti M \& Legrand A (2000) Biomarkers of oxidative stress: an analytical approach. Curr Opin Clin Nutr Metab Care 3, 373-384.

43. Roberts LJ II, Montine TJ, Markesbery WR, Tapper AR, Hardy P, Chemtob S, Dettbarn WD \& Morrow JD (1998) Formation of isoprostane-like compounds (neuroprostanes) in vivo from docosahexaenoic acid. Formation of isoprostane-like compounds (neuroprostanes) in vivo from docosahexaenoic acid. $J$ Biol Chem 273, 13605-13612.

44. Basu S (1998) Metabolism of 8-iso-prostaglandin F2 $\alpha$. FEBS Lett 428, 32-36.

45. Lee CYJ, Isaac HB, Wang H, Huang SH, Long LH, Jenner AM, Kelly RP \& Halliwell B (2006) Cautions in the use of biomarkers of oxidative damage; the vascular and antioxidant effects of dark soy sauce in humans. Biochem Biophys Res Commum 344, 906-911.

46. Chirico S, Smith C, Marchant C, Mitchinson MJ \& Halliwell B (1993) Lipid peroxidation in hyperlipidaemic patients. A study of plasma using an HPLC-based thiobarbituric acid test. Free Radic Res Commun 19, 51-57.

47. Prior RL, Cao G, Prior RL \& Cao G (2000) Analysis of botanicals and dietary supplements for antioxidant capacity: a review. J AOAC Int 83, 950-956.

48. Sacks FM, Lichtenstein A, Van Horn L, Harris W, KrisEtherton P \& Winston M (2006) American Heart Association Nutrition Committee Soy protein, isoflavones, and cardiovascular health: an American Heart Association Science Advisory for professionals from the Nutrition Committee. Circulation 113, 1034-1044.

49. Sacks FM (2005) Dietary phytoestrogens to prevent cardiovascular disease: early promise unfulfilled. Circulation 111, 385-387.

50. Lotito SB \& Frei B (2006) Consumption of flavonoid-rich foods and increased plasma antioxidant capacity in humans: cause, consequence, or epiphenomenon? Free Radic Biol Med 41, 1727-1746. 